\title{
Pelestarian Kebudayaan Peranakan Tionghoa Wayang Potehi melalui Media Digital
}

\author{
Natalia, Widayatmoko \\ Natalialia682@gmail.com
}

Fakultas Ilmu Komunikasi Universitas Tarumanagara

\begin{abstract}
Indonesia has a diversity of cultures, one of which is the Chinese Peranakan culture "Wayang Potehi" which is a culture resulting from the acculturation of Chinese migrants who settled in the Java archipelago. However, when the new order of Potehi Puppets was banned from being played, it had experienced torpor. To revive the Potehi Puppet is not an easy thing, so it needs preservation and contextualized with today's development, namely by using digital media. This study describes the preservation of the Potehi Puppet Chinese culture by using digital media, here the author uses qualitative methods to find out how the preservation of Potehi Puppets uses digital media. The researcher observed and conducted interviews with the Potehi Puppet sources, namely the Potehi Puppet experts, the Chinese Peranakan Association, the mastermind, and the audience coaches. Based on the results of the study through interviews and observations that the preservation of Potehi Puppet is not only directly through the event but also by using digital media such as websites, Blogs, Youtube, and various social media uses also because of the rapid spread and the target is the younger generation.
\end{abstract}

Keywords: preservation, theory of culture, media digital

\begin{abstract}
Abstrak
Indonesia memiliki keberagaman budaya, salah satunya adalah budaya Peranakan Tionghoa "Wayang Potehi" yang merupakan kebudayaan hasil akulturasi migran Cina yang menetap di kepulauan Jawa. Namun, pada saat Orde Baru, Wayang Potehi dilarang untuk dimainkan sehingga sempat mengalami mati suri. Untuk menghidupkan kembali Wayang Potehi bukan suatu hal yang mudah, maka dari itu butuh pelestarian dan dikontekstualkan dengan perkembangan zaman sekarang ini yaitu dengan menggunakan media digital. Penelitian ini menggambarkan pelestarian kebudayaan Peranakan Tionghoa Wayang Potehi dengan menggunakan media digital. Di sini penulis menggunakan metode kualitatif untuk mengetahui bagaimana pelestarian Wayang Potehi menggunakan media digital. Peneliti melakukan observasi dan melakukan wawancara kepada sumber Wayang Potehi yaitu pakar Wayang Potehi, Pembina Asosiasi Peranakan Tionghoa, dalang, dan penonton. Berdasarkan hasil penelitian melalui wawancara dan observasi bahwa pelestarian Wayang Potehi tidak hanya secara langsung melalu acara namun juga dengan menggunakan media digital seperti website, Blog, Youtube, dan berbagai penggunaan media sosial juga karena penyebaran yang cepat dan targetnya adalah generasi muda.
\end{abstract}

Kata Kunci: Pelestarian, Teori kebudayaan, Media digital 


\section{Pendahuluan}

Wayang Potehi merupakan kesenian hasil akulturasi yang dibawa oleh perantau etnis Tionghoa ke berbagai wilayah Nusantara pada masa lampau dan telah menjadi salah satu jenis kesenian tradisional Indonesia. Pada era saat ini, kemajuan teknologi sangat berkembang pesat sehingga bentuk komunikasi melalui media digital dapat menyebarkan suatu informasi secara serentak. Menurut Kamus Besar Bahasa Indonesia (KBBI), media merupakan alat, sarana, perantara atau penghubung. Digital merupakan jaringan online. Jadi media digital merupakan bentuk media elektronik. Hal ini diperkuat oleh Terry Flew dalam buku yang berjudul "New Media: An Introduction" menjelaskan bahwa terdapat ciri media baru yaitu digital, interaktif, virtual, jaringan, dan simulasi (Widayatmoko, Diah Ayu Candraningrum, Budi Utami., et al 2018)

Pelestarian didasarkan pada kecenderungan manusia untuk melestarikan nilainilai budaya sehingga masih memiliki arti untuk generasi selanjutnya. Pelestarian didefinisikan sebagai menjaga sesuatu dari serangan/kerusakan sehingga tetap dalam kondisi yang baik (Hanni et.al, 2012). Secara umum pelestarian sebagai suatu usaha atau kegiatan untuk merawat, melindungi, dan mengembangkan sehingga tetap menjaga nilai-nilai yang ada. Menurut A.W. Widjaja, pelestarian sebagai kegiatan atau yang dilakukan secara terus menerus, terarah dan terpadu guna mewujudkan tujuan tertentu yang mencerminkan adanya sesuatu yang tetap dan abadi, bersifat dinamis, luwes, dan selektif (Siska et al, 2014)

Berdasarkan penjelasan di atas, pelestarian kebudayaan tidak bisa berdiri sendiri. Perlu adanya campur tangan individu untuk melakukan pelestarian kebudayaan guna menjaga nilai-nilai dan budaya yang ada serta mengembangkannya sesuai dengan perkembangan yang ada saat ini.

Akulturasi di Jawa, proses percampuran kebudayaan Cina telah melewati suatu masa yang panjang. Pada abad ke-17 terutama dalam masa kekuasaan Dinasti Qing (1644-1911), budaya Tionghoa dibawa oleh imigran China ke arah laut China Selatan hingga ke Jawa. Sebagian besar unsur budaya Tionghoa lambat laun melebur dengan unsur budaya yang ada di Jawa. Mayoritas anggota masyarakat Tionghoa di Indonesia terdiri atas suku Hakka (Khek) atau Hokkian. Suku Khek terdapat di provinsi Sumatra dan Kalimantan, sedangkan suku Hokkian di pulau Jawa. Suku Hokkian memasuki Pulau Jawa melalui pelabuhan-pelabuhan yang berada di Pantai Utara (Woro, 2014).

Berdasarkan beberapa pengertian, maka kebudayaan Tionghoa yaitu "Wayang Potehi" yang merupakan kebudayaan hasil akulturasi Cina-Jawa. Akulturasi budaya itu dapat tercemin dari produknya. Wayang Potehi yang berasal dari Tionghoa telah tumbuh bersama kebudayaan lokal dan melebur menjadi budaya Indonesia

Penulis ingin meneliti Wayang Potehi karena ada keunikan yaitu perpaduan antara wayang kulit dengan wayang cina akibat hasil akulturasi dan salah satu organisasinya yaitu Asosiasi Peranakan Tionghoa (ASPERTINA) dalam melestarikan budaya peranakan Tionghoa yaitu "Wayang Potehi" melalui penggunaan media digital sekarang ini. Penulis melihat bahwa Asosiasi Peranakan Tionghoa ini merupakan suatu organisasi dengan tujuan untuk melestarikan suatu kebudayaan yakni kebudayaan Tionghoa.

Berdasarkan judul penelitian di atas, rumusan masalah yang menjadi fokus dalam penelitian ini adalah bagaimana pelestarian budaya Tionghoa "Wayang Potehi" melalui media digital (Asosiasi Peranakan Tionghoa) ASPERTINA? 
Tujuan penelitian ini untuk mengetahui pemanfaatan media digital dalam melestarikan kebudayaan sehingga dari generasi ke generasi, pelestarian bisa terus dilakukan.

\section{Metode Penelitian}

Penelitian ini dilakukan untuk memahami pelestarian budaya Peranakan Tionghoa "Wayang Potehi". Pendekatan yang dilakukan peneliti dalam penelitian ini adalah pendekatan kualitatif. Menurut Denzin dan Lincoln (dalam Moleong, 2008) penelitian kualitatif adalah penelitian yang menggunakan latar alamiah dengan maksud menafsirkan fenomena yang terjadi dan dilakukan dengan jalan melibatkan metode yang ada.

Menurut Bodgan dan Taylor (dalam Basrowi dan Suwandi, 2008), penelitian kualitatif adalah salah satu prosedur penelitian yang menghasilkan data deskriptif berupa ucapan atau tulisan dan perilaku orang-orang yang diamati.

Berdasarkan beberapa pengertian di atas dapat disimpulkan bahwa penelitian kualitatif yang dilakukan adalah untuk mendapatkan data atau informasi sebenarbenarnya serta memberikan pemahaman menyeluruh tentang pelestarian kebudayaan Peranakan Tionghoa "Wayang Potehi" dalam Asosiasi Peranakan Tionghoa. Dalam pemilihan jenis penelitian ini, peneliti memilih menggunakan jenis penelitian deskriptif kualitatif. Penelitian deskripif kualitatif bertujuan untuk menggambarkan, meringkas berbagai kondisi, situasi, ata berbagai fenomena realitas social yang ada dimasyarakat yang menjadi objek penelitian dan berupaya menarik realitas itu ke permukaan sebagai ciri, karakter atau gambaran tentang kondisi atau situasi tertentu. (Bungin, 2008)

Pada penelitian ini peneliti menggunakan jenis penelitian kualitatif yang bersifat deskriptif untuk mengetahui dengan jelas bagaimana pelestarian kebudayaan peranakan Tionghoa melalui media digital. Oleh karena itu, dalam laporan penelitian ini akan berisi kutipan data untuk memberi gambaran penyajian laporan tersebut. Dalam penelitian ini, strategi yang digunakan ialah studi kasus. Studi kasus adalah eksplorasi seuah program, suatu peristiwa, suatu kegiatan atau individu dari sebuah sistem yang terbatasi oleh waktu dan tempat. (Yusuf, 2014)

Penelitian ini menggunakan metode studi kasus untuk dapat menjelaskan mengenai pandangan subjek dan objek yang diteliti tentang bagaimana melakukan pelestarian kebudayaan peranakan Tionghoa "Wayang Potehi".

\section{Hasil Temuan dan Diskusi}

Setelah melakukan wawancara kepada beberapa narasumber dan melakukan observasi. Peneliti menemukan bahwa Wayang Potehi memiliki perjalanan yang cukup panjang sampai saat ini hingga bisa masuk ke dalam daftar wayang di Ensiklopedia Wayang International pada tahun 2006. Ibu Dwi Woro selaku pakar dari Wayang Potehi yang menjadi narasumber penulis mendirikan rumah cinwa (Cinta Wayang) sejak tahun 2014 dan bekerja sama dengan Asosiasi Peranakan Tionghoa dalam pelestarian Wayang Potehi melalui media digital. Perjalanan untuk mengangkat Wayang Potehi ke atas permukaan setelah lama terkubur bukanlah hal yang mudah, seperti penuturan Ibu Dwi Woro yang menceritakan tentang perjalanannya kepada peneliti pada saat wawancara berlangsung pada tanggal 10 November 2018. Peneliti 
juga membaca artikel dan gambar yang di unggah sebagai bentuk pelestarian dengan menggunakan media digital untuk mempekenalkan Wayang Potehi.

Wayang Potehi merupakan kebudayaan peranakan Tionghoa. Budaya merupakan sebuah tatanan pengetahuan, pengalaman, kepercayaan, nilai, sikap, makna, hirarki, agama, waktu, peranan, hubungan ruang, konsep alam semesta, objekobjek materi dan milik yang diperoleh sekelompok besar orang dari generasi ke generasi melalui usaha dan kelompok. Budaya menampakkan diri dalam pola-pola bahasa dan gaya komunikasi orang-orang yang tinggal dalam suatu masyarakat. Budaya juga berkenaan dengan objek seperti rumah, alat dan mesin, dan lainnya (Mulyana \& Rakhmat, 2015).

Salah satunya ialah kebudayaan hasil akulturasi Cina Jawa yaitu Wayang Potehi yang dibawa oleh imigran Cina ke Pulau Jawa yang tujuan awalnya hanyalah untuk mendapat kehidupan yang lebih layak. Namun seiring berjalannya waktu terjadilah sebuah adaptasi budaya Tionghoa dengan budaya pribumi atau Jawa yang melahirkan Wayang Potehi. Pada pertunjukkan Wayang Potehi ada yang memainkan alat musik yang mirip seperti gamelan dan permainan wayang yang berlangsung. Akulturasi merupakan proses alamiah atau suatu proses yang dilakukan imigran untuk menyesuaikan diri dengan dan memperoleh budaya pribumi (Mulyana dan Rakhmat, 2009).

Pada saat memasuki Orde Baru, Wayang Potehi kehilangan masa jayanya dan sempat mati suri selama 33 tahun berlangsung dari tahun 1965-1998. Pada masa-masa inilah hal yang berhubungan dengan Tiongkok tidak diijinkan tampil di depan umum atau publik. Pada zaman kepemimpinan Soeharto banyak sekali kebijakan yang dibuat sehingga pada saat itu kesenian yang berbau Tionghoa tidak boleh ditampilkan secara terang-terangan. Wayang Potehi hanya bisa dimainkan dalam rumah atau kelenteng, namun menurut pernyataan ibu Dwi Woro menyatakan bahwa terkadang masih saja ketika tampil di klenteng ada orang pemerintahan yang merazia berlangsungnya Wayang Potehi tersebut. Jadi pada saat itu cukup sulit untuk melakukan pementasan Wayang Potehi karena peraturan yang dibuat pada saat itu di zaman pemerintahan orde baru.

Wayang Potehi baru mulai dapat tampil lagi pada saat zaman reformasi dimana masyarakat Tionghoa Peranakan Indonesia boleh dengan bebas menampilkan kebudayaannya di depan umum dan bahkan Hari Raya Imlek pun mendapat pengakuan pada saat kepemimpinan Abbdurahman Wahid yang berkedudukan sebagai presiden dan mencabut Peraturan Pemerintah No. 14/1967.

Maka dari itu barulah Wayang Potehi dapat dipertunjukkan dengan bebas. Namun, setelah mati suri perlu adanya sebuah gerakan untuk generasi berikutnya tetap bisa mengenal kebudayaan peranakan Tionghoa yang menjadi warisan kebudayaan Indonesia. Hal yang dilakukan oleh Ibu Dwi Woro ialah melakukan pelestarian terhadap kebudayaan yang telah mati suri untuk membangkitkan lagi kebudayaan Peranakan Tionghoa tersebut. Salah satu bentuk pelestarian yang dilakukan oleh Ibu Dwi Woro adalah melalui pementasan Wayang Potehi. Pementasan Wayang Potehi dilakukan di berbagai tempat di Jakarta.

Para penonton pementasan Wayang Potehi berasal dari berbagai strata usia bahkan terkadang Wayang Potehi tampil di kalangan anak kecil atau TK, salah satunya di TK Penabur 10, Jakarta Utara. Pementasan Wayang Potehi menyuguhkan nilai-nilai yang mengandung moral dari cerita-cerita yang dibawakan oleh dalang seperti pada saat tampil di TK Penabur, di mana yang menjadi penonton adalah anak-anak yang berusia di bawah 5 tahun ditemani oleh orang tua atau pengasuhnya. Jumlah penonton 
tidak selalu sama, namun dengan adanya pementasan tersebut penyampaian nilai moral dan pengenalan akan suatu kebudayaan tetap tersampaikan. Pelestarian adalah upaya untuk menjaga sesuatu dari kerusakan atau serangan sehingga tetap ada dan dalam kondisi yang baik (Hani et.al, 2012).

Pelestarian Wayang Potehi merupakan upaya untuk melestarikan nilai-nilai budaya sehingga tetap terjaga dan memiliki arti untuk generasi selanjutnya. Pelestarian kebudayaan juga memerlukan campur tangan individu untuk melestarikan dan menjaga kebudayaan tersebut untuk diwariskan dari generasi ke generasi berikutnya agar kebudayaan tersebut tetap terjaga dan tidak hilang begitu saja. Cerita-cerita yang dibawakan dalam pementasan merupakan cerita-cerita asli pada saat sebelum Orde Baru, naskah cerita Wayang Potehi yang dikumpulkan oleh Ibu Dwi Woro pada saat ia melakukan penelitian namun cerita-cerita tersebut dibawakan dengan relevansi penonton, seperti anak TK maka ada cerita tambahan yaitu cerita binatang, pelestarian yang dilakukan juga menggunakan media digital seiring dengan perkembangan zaman sekarang ini yang dapat disebarluaskan dengan cepat dan di akses kapan pun pada website rumah Cinwa dan Asosiasi Peranakan Tionghoa serta dengan menggunakan media sosial yang dimiliki sebagai bentuk pelestaian menggunakan media digital. Penggunaan media digital seperti penggunggahan video, foto boneka Wayang Potehi. Penggunaan teknologi zaman sekarang ini mengalami peningkatan sehingga meningkatkan penggunaan media digital. Media digital (modern) merupakan penggunaan teknologi komputer yang menggabungkan berbagai bentuk media ke dalam bentuk digital. Media digital adalah media elektronik yang menggunakan kode digital untuk membuat konten, suara, gambar atau video (Adrian, 2013).

Pelestarian Wayang Potehi juga memanfaatkan media sosial sebagai bentuk pelestarian dalam media digital, seperti salah satunya menggunakan Youtube. Video yang diunggah ke dalam Youtube oleh Rumah Cinwa. Youtube merupakan tempat orang berbagi video, mencari, dan lainnya. Youtube sebagai media baru penerus (Uricchio, et.al 2009). Tidak hanya itu saja, namun meggunakan wordpress yang dituliskan tentang perjalanan Wayang Potehi, pagelaran acara, serta acara yang akan datang baik yang ditulis oleh Rumah Cinwa ataupun Asosiasi Peranakan Tionghoa di website.

Jadwal pementasan Wayang Potehi, serta artikel yang menuliskan asal usul Wayang Potehi. Pelestarian Wayang Potehi tidak hanya secara fisik yang nyata, namun juga cerita dari Wayang Potehi yang memberi nilai pada kehidupan. Nilai-nilai kebaikan, kejujuran yang harus diterapkan dalam kehidupan.

\section{Simpulan}

Berdasarkan dari hasil penelitian dan observasi serta analisis data yang penulis lakukan mengenai bagaimana pelestarian kebudayaan Peranakan Tionghoa Wayang Potehi melalui media digital, maka dapat ditarik kesimpulan sebagai berikut:

1) Wayang Potehi merupakan kebudayaan peranakan Tionghoa yang dibawa oleh Migrasi Cina ke Kepulauan Jawa. Migrasi Cina yang pindah ke kepulauan Jawa untuk mendapatkan kehidupan yang lebih layak dan menetap di kepulauan Jawa. Wayang Potehi merupakan hasil akulturasi yang disebabkan oleh migrasi Cina yang menetap di kepulauan Jawa, sehingga pada masa itu kebudayaan Cina yang di kolaborasikan dengan kebudayaan Jawa sehingga lahirlah Wayang Potehi. Namun Wayang Potehi sempat mati suri sehingga pada kejayaan Wayang Potehi menurun hingga pada zaman kepemimpinan 
Presiden Gus Dur maka Wayang Potehi baru mulai dimainkan kembali. Pelestarian wayang potehi tidak hanya secara fisik dan pagelaran acara, namun juga nilai yang terkandung dalam cerita yang dibawakan dalam pertunjukkan Wayang Potehi. Makna dan nilai yang terkandung penting bagi kehidupan manusia.

2) Wayang Potehi kini dilestarikan juga dengan memanfaatkan media digital, dengan perkembangan zaman sekarang ini yang semua serba cepat maka media digital merupakan pilihan yang sesuai serta yang menjadi target pelestarian Wayang Potehi merupakan generasi muda.

\section{Ucapan Terima Kasih}

Puji dan syukur penulis panjatkan kepada Tuhan Yesus Kristus untuk segala berkat, rahmat-Nya bagi penulis sehingga dapat menyelesaikan penelitian ini yang berjudul "Pelestarian Kebudayaan Peranakan Tionghoa Wayang Potehi Melalui Media Digital" dengan tepat waktu.

Pada kesempatan ini penulis ingin mengucapkan terimakasih kepada pihakpihak yang telah membantu dan memberi dukungan secara langsung maupun tidak langsung selama proses penulisan skripsi ini. Kepada segenap dosen Fakultas Ilmu Komunikasi yang telah mengajarkan penulis selama perkuliahan; Asosiasi Peranakan Tionghoa (ASPERTINA) yang telah mengijinkan menulis melakukan penelitian mengenai kebudayaan peranakan Tionghoa serta memperkenalkan penulis kepada dewan pakar Wayang Potehi. Sejumlah narasumber yang telah meluangkan waktu yakni Bapak Hendry, Bapak Antryz, Ibu Dwi Woro, serta pemain dalang.

Terimakasih penulis haturkan untuk keluarga, Mama, tante, saudara yang selalu memberi dukungan berupa doa dan semangat.

\section{Daftar Pustaka}

Alo, Liliweri, (2011). Komunikasi Serba Ada Serba Makna. Jakarta: Prenada Media Grup

Bhakti, Andi Faisal, dkk. (2017). Literasi Politik dan Kampanye Pemilu. Churia (Center for Human Rights in Action)

Burgess, J., \& Green, J. (2009). Youtube: Online video and participatory culture. Cambridge, UK: Polity

Cangara, Hafied. (2012). Pengantar Ilmu Komunikasi. Jakarta: PT. Raja Grafindo Persada

Flew, Terry (2008). New Media, An Introduction. Oxford University Press, Oxford.

Gillin, J. L., Gillin, P. (1954). Cultural Sociology. A revision of an Introduction to Sociology. New York: The Macmillan Company

Gunawan, Imam. (2013). Metode Penelitian Kualitatif. Jakarta: Bumi Aksara

John, Little (2012). Komunikasi Antar Budaya. Bandung: CV Mustika

Juditha, Christiany. (2015). Stereotip dan Prasangka dalam Konflik Etnis Tionghoa dan Bugis Makassar. Jurnal Ilmu Komunikasi. 12 (1). 87-104

Mondry. (2008). Teori dan praktik Jurnalistik. Bogor: Ghalia Indonesia.

Na'im, Akhsan., \& Hendry Syaputra. (2011). Kewarganegaraan, Suku Bangsa, Agama, dan Bahasa Sehari-Hari Penduduk Indonesia. Oktober 2011. Diakses $\begin{array}{llll}\text { pada } & 10 & \text { September }\end{array}$ http://demografi.bps.go.id/phpfiletree/bahan/kumpulan_tugas_ 
mobilitas_pak_chotib/Kelompok_1/Referensi/BPS_kewarganegaraan_sukuban gsa_agama_bahasa_2010.pdf

Nazir, Moh, Ph.D. (2013). Metode Penelitian. Bogor: Penerbit Ghalia Indonesia

Onghokham. (2017). Migrasi Cina, Kapitalisme Cina dan Anti Cina. Depok: Komunitas Bambu.

Paramita, Sinta., \& Wulan P. Sari. (2016). Komunikasi Lintas Budaya dalam Menjaga Kerukunan antara Umat Beragama di Kampung Jaton Minahasa. Jurnal Komunikasi. 1 (2). 156-157

R Wayne and Faules, Don F. (2006). Komunikasi Organisasi. Terjemahan. Bandung: Rosdakarya

Samovar, L. A., Porter, R. E, \& McDaniel, E. R. (2010). Komunikasi Lintas Budaya (Edisi 7). Jakarta: Salemba Humanika

Setiadi, Elly. (2012). Ilmu Sosial dan Budaya Dasar. Jakarta: Kencana Prenada Grup.

Soekanto, Soerjono. (2012). Sosiologi Suatu Pengantar. Jakarta: Rajawali Pers

Straubhaar, Joseph; Robert LaRose; Lucinda Davenport (2010). Media Now, Understanding Media, Culture and Technology, Wadsworth Cengage Learning, Boston, Boston.

Sugiyono. (2011). Metode Penelitian Pendidikan. Bandung: Alfabeta.

Uricchio, W. (2009). The future of a medium once known as television. In Pelle Snickars, \& Patrick Vonderau (eds), The Youtube Reader (p. 24-39). London, UK: Wallflower Press.

Widayatmoko, Diah Ayu, Budi Utami. (2018). Etika dan budaya berinteraksi di media sosial di SMA Surakarta. Vol.1 No.1 (p.29)

Wiryanto (2006). Teori Komunikasi Massa. Grasindo, Jakarta.

Woro, Dwi. (2014). Wayang Potehi. Jakarta: Sinar Harapan

Zarella, Dan. (2010). The Social Media Book. Gravenstein Highway North: O'Reilly Media Inc. 